\title{
DA CRÍTICA À SUPERQUADRA AO QUARTEIRÃO MURADO: O CASO DE ÁGUAS CLARAS EM BRASÍLIA
}

\author{
LUCAS BRASIL PEREIRA \\ Universidade de Brasília, Faculdade de Arquitetura e Urbanismo/ \\ Universidade de Coimbra, Faculdade de Economia. Faculdade de Arquitetura \\ e Urbanismo, UnB: Instituto Central de Ciências - ICC Norte - Gleba A, \\ Campus Universitário Darcy Ribeiro - Asa Norte, CEP: 70842-970 - Brasília, \\ DF, Brasil. / Telefone PPG-FAU: + 55 (61) 3107-7441 / 7442 \\ https://orcid.org/0000-0002-3330-5164 \\ lucasbrasilp@gmail.com
}

\section{LUCIANA SABOIA FONSECA CRUZ}

Universidade de Brasília, Faculdade de Arquitetura e Urbanismo. Faculdade de Arquitetura e Urbanismo, UnB: Instituto Central de Ciências - ICC Norte - Gleba A, Campus Universitário Darcy Ribeiro - Asa Norte, CEP: 70842-970 - Brasília, DF, Brasil. / Telefone PPG-FAU: + 55 (61) 3107$7441 / 7442$

https://orcid.org/0000-0002-9169-0515

lucianasaboia@unb.br

\section{RESUMO}

Este artigo discute processos envolvidos na transformação da materialidade de Águas Claras, bairro planejado em Brasília, Distrito Federal, cujo projeto aspirava mimetizar as ruas e as avenidas com largas calçadas típicas das ditas "cidades tradicionais" em contraposição ao modelo urbanístico de matriz modernista - amplos espaços verdes, vias separadas dos fluxos de pedestres e edifícios isolados - que caracteriza o Plano Piloto de Brasília, localizado apenas a 19 quilômetros do sítio analisado. Para além da crítica estabelecida acerca de Brasília enquanto tema urbanístico, Águas Claras caracteriza-se como ruptura na paisagem metropolitana da região, antes marcada pela horizontalidade de suas cidades satélites e pela ocupação dispersa no território. A intensa verticalização, muito superior aos 12 pavimentos previstos inicialmente no projeto de Paulo Zimbres contratado em 1991, configura quadras muradas como pequenos condomínios fechados, apesar das premissas de profusos espaços públicos em seu projeto. Este estudo discute as ambiguidades do projeto enquanto narrativa de disputa e conflito que (re)configura o território e a paisagem ao longo do tempo. Surgem como conclusões principais a maneira pela qual a questão do projeto atravessa modelos urbanísticos substancialmente distintos, ainda que de maneiras variadas, além de apontamentos acerca da tortuosa relação entre projeto urbanístico, aspirações de modernidade, classes sociais e legislação urbanística.

Palavras-chave: Águas Claras. Brasília. Projeto urbano. Superquadra. Muros.
Recebido: 23/09/2020

Aceito: 06/01/2021

\section{ABSTRACT}

This paper discusses processes involved in the transformation of Águas Claras' materiality, a neighbourhood designed in Brasília, Federal District, whose project aspired to mimic the streets and the avenues with wide sidewalks typical of the socalled "traditional cities" as opposed to the modernist urban model - ample green spaces, roads separated from pedestrian flows and isolated buildings - that characterizes the Pilot Plan of Brasília, located only 19 kilometers from the analyzed site. In addition to the criticism established about Brasília as urban subject, Águas Claras is characterized as a break in the metropolitan landscape of the region, previously marked by the horizontality of its satellite cities and by the disperse occupation of the territory. The intense verticalization, much higher than the 12 floors initially foreseen in Paulo Zimbres' design contracted in 1991, configures walled blocks as small closed condominiums, despite the premises of profuse public spaces in his design. This study discusses the ambiguities of the design as a narrative of dispute and conflict that (re) configures the territory and the landscape over time. The main conclusions are the way in which the issue of design crosses substantially different urban models, albeit in different ways, in addition to observations about the tortuous relationship between urban design, aspirations of modernity, social classes and urban legislation.

Keywords: Aguas Claras. Brasilia. Superblocks. Walls. Urban design. 


\section{INTRODUÇÃO}

O projeto de Brasília e sua construção são por vezes reconhecidos ou enunciados na literatura (BENEVOLO, 2005; FICHER, 2009; FRAMPTON, 1997; VIDAL, 2009) como apogeu da realização do Movimento Moderno, manifestando princípios e paradigmas dos CIAM - Congrès Internationaux d'Architecture Moderne -, influente fórum de debates na primeira metade do século XX. O projeto vencedor do Plano Piloto para a nova capital brasileira, de autoria de Lucio Costa em 1957, cruza dois eixos perpendiculares, o Monumental e o Rodoviário, onde o primeiro abriga as praças cívicas, os palácios e as edificações governamentais e o segundo eixo configura um amplo bosque entremeado por blocos habitacionais de até seis pavimentos e sobre pilotis livres e de acesso público, liberando o chão gramado e intensamente arborizado para uso comum.

Esse componente paisagístico-urbanístico marca profundamente Brasília. A inspiração no ideário de cidade-parque era patente. A composição de cada superquadra acabaria por remeter à de um pátio interno, sendo cercada de uma faixa arbórea, onde - segundo Costa - mesmo os moradores dos pavimentos mais altos poderiam ter contato visual com crianças brincando nas áreas verdes e de lazer infantil no interior da quadra. Assim, dada sua configuração, a Superquadra do Plano Piloto representou uma ruptura em relação ao modelo do quarteirão urbano tradicional desenhado pela propriedade de lotes e limites entre o público e o privado.

O debate e a crítica intensificada na década de 1980 no Brasil tiveram como foco o rarefeito adensamento nos planos urbanísticos de matriz modernista, ou seja, o esparçamento na ocupação do solo urbano devido à profusão de espaços vazios e verdes, o que configuraria uma oposição à morfologia do quarteirão parcelado em lotes com edificações contíguas, onde somente as fachadas frontais dão face à rua, comuns nas cidades europeias, as quais Le Corbusier intitulava rue-corridor (CORBUSIER, 2004[1930]). Somada ao uso excessivo do transporte individual, essa característica foi um dos elementos mais marcantes das críticas orientadas ao desenho urbano do Plano Piloto de Brasília (BICCA, 1985; HOLANDA, 1985a; HOLSTON, 1993 [1989]; FRAMPTON, 1997). A falta "esquinas" em quarteirões para encontros fortuitos e o desenho viário voltado para o automóvel foram os principais argumentos que reverberaram a já consolidada crítica aos preceitos do Movimento Moderno como um todo (JACOBS, 2011[1961]; VENTURI, 2004[1966]; HALL, 2013[1988]), passando por autores como Vicente Del Rio (1990), Juan Luis Mascaró (1987) e Carlos Nelson dos Santos (1988). Recentemente, continuam a ser reeditados por autores como Jan Gehl (2014) e Rem Koolhaas (2016). O que se percebe é que Brasília foi de tese a antítese.

A partir da crítica cultivada no contexto de busca por novos modelos urbanísticos alternativos ao Plano Piloto de Brasília, nasce Águas Claras, fruto de uma diretriz de planejamento orientada para consolidar o eixo de urbanização ao longo da Estrada Parque Taguatinga - EPTG, via de acesso ao Plano Piloto. Pouco depois, a criação de Águas Claras passaria a ser uma das principais agendas da política habitacional na região sudoeste do Distrito Federal, preenchendo um hiato territorial entre ocupações adjacentes ao Plano Piloto e Taguatinga, Ceilândia e da então recém-criada Samambaia, à época ainda chamadas de "cidades-satélites".

A cidade foi planejada segundo paradigmas urbanísticos que privilegiavam tipologias tradicionais com quarteirões com largas calçadas e galerias comerciais nos pavimentos inferiores que serviriam de base para edificações residenciais em altura até 12 pavimentos. Haveria uma nova coalizão entre a circulação de pedestres e veículos na retomada de ruas-corredores, caracterizados como boulevards, especialmente nas duas principais avenidas da cidade ao longo da linha do metrô. As duas avenidas configuravam o traçado regula- 
dor do projeto: os quarteirões dispostos em quadras paralelas eram formados por lotes que delimitavam a interface entre o uso público e privado no solo urbano.

Entretanto, uma outra paisagem em Águas Claras ergue-se após mais de três décadas de seu projeto. Hoje a Região Administrativa de Águas Claras no Distrito Federal ${ }^{1}$ chama atenção no horizonte de uma Brasília-metrópole. Isso ocorre principalmente devido à sua concentração de edifícios de grande altura, muitos dos quais alcançam 36 pavimentos. A acentuada verticalização contrasta com a restante urbanização espraiada e é substancialmente diferente daquela representada pelos autores do projeto do bairro nas antevisões embutidas nas perspectivas do projeto urbanístico.

Muitas das galerias comerciais sugeridas no plano urbanístico não foram acatadas pelas construtoras e cooperativas habitacionais que deram início às primeiras construções. Apesar da possibilidade do uso comercial, muitas das edificações decidiram por uma tipologia comum da paisagem brasiliense: o térreo em pilotis com áreas coletivas para seus moradores, mas com o limite do lote cercado para privacidade e controle dos condôminos.

À altura do chão, grades e muros foram elevados ao longo do percurso de pedestres e compõem uma outra paisagem em Águas Claras, refletindo o modelo de enclave que ali se erigiu. Câmeras de segurança e holofotes vigiam esquinas e ruas enquanto equipamentos de lazer já presentes em praças ou normalmente encontrados em áreas públicas são oferecidos nas áreas internas dos condomínios. O conjunto desses elementos tem impacto marcante na configuração de uma paisagem murada com pouca interface com as ruas e avenidas que constituem os quarteirões, salvo por poucas exceções.

É importante salientar que existe uma extensa bibliografia acerca dos aspectos relativos às características ambientais e sustentabilidade ${ }^{2}$ em Águas Claras, mas este artigo propõe abordar e contribuir com o escasso debate referente a um aspecto específico da materialização e redefinição do projeto. Reconhece-se que, apesar de tentar desvincular-se do projeto do Plano Piloto, Águas Claras acabou por incorporar parte de seus elementos urbanísticos - como edificações em pilotis e edificações isoladas em algumas quadras, para citar alguns exemplos -, mas os posicionando entre muros.

Dessa maneira, este trabalho parte da crítica esboçada às superquadras de Brasília e à sua composição, avançando ao discutir a intencionalidade de constituir em Águas Claras o quarteirão e assumindo como referência a rua-corredor. Em seguida, argumenta-se que as críticas a alguns dos princípios do Movimento Moderno alimentaram sobremaneira o projeto de Águas Claras na construção de uma dicotomia, principalmente em seu argumento e representação, mas que isso foi insuficiente para uma materialização precisa do projeto e para a superação das questões elencadas pela crítica. Além disso, nota-se que, apesar de diversos pontos de convergência com o projeto original serem percebidos hodiernamente na materialidade do novo bairro, coexistem com a presença de características não desejadas e que estão desvinculadas da crítica ao Plano Piloto de Brasília.

\footnotetext{
${ }^{1}$ Regiões Administrativas (RAs) são uma subdivisão da administração do Distrito Federal. Seus limites físicos (poligonais) definem áreas de atuação e jurisdição de administrações locais, propiciando uma coordenação governamental local e menos centralizada.

${ }^{2}$ Essa bibliografia trata principalmente de aspectos como ruídos, ilhas de calor, eficiência energética, enfim, características ambientais de Águas Claras, assim como lida com tópicos em sustentabilidade, desempenho energético e aspectos construtivos que assumem o bairro como caso específico (GARAVELLI, MORAES, NASCIMENTO, NASCIMENTO, \& MAROJA, 2010; CAMPANHONI, Implantação dos edifícios em Águas Claras-DF: influência no desempenho térmico ambiental dos espaços abertos, 2011; FERNANDES, BAPTISTA, \& BIAS, 2011; OLIVEIRA, SPOSITO, \& BLUMENSCHEIN, 2012; LIMA \& SOUZA, 2014; CARVALHO JÚNIOR, et al., 2016). Com relação à gênese e às transformações levadas a cabo em Águas Claras, há publicada alguma bibliografia (WILLIAMS, 2007; PAVIANI, 2010a; 2010b; SERRANO, 2010; CAMPANHONI, 2013; SILVA, 2016) e há também pontuais teses e dissertações que se debruçam sobre o caso (FRANÇA, 2008; OLIVEIRA M. E., 2009; PEREIRA 2016).
} 
QUESTÕES DE PROJETO: A SUPERQUADRA DO PLANO PILOTO E A RETOMADA DO QUARTEIRÃO EM ÁGUAS CLARAS

É no projeto do Plano Piloto que a materialidade construída pôde ser observada e julgada com mais ênfase como a mais fiel realização dos preceitos da Carta de Atenas. Como já apontou Kenneth Frampton (1997), a declaração produzida no primeiro CIAM, em 1928, entendia que a atividade construtiva deveria estar intimamente ligada à evolução e ao desenvolvimento da vida humana. O conjunto de ideias gestado nessa série de eventos veio a ser sistematizado no documento intitulado "Carta de Atenas", produto do IV CIAM, em 1933. No referido documento, diversos artigos apontavam como deveria ser pensada a cidade do século XX: reconhecida, fundamentalmente, como A Cidade Funcional (FRAMPTON, 1997). Os debates que levaram a essa concepção foram fruto da realidade do século XIX, quando, por um lado, ganharam relevo os problemas sanitários nos centros urbanos e, por outro, houve acelerado surgimento de tecnologias advindas de máquinas que possibilitavam transformações nos modos de vida das populações (SECCHI, 2009).

A Carta emanava a racionalidade moderna do ocidente do norte-global. Fazia isso ao compreender a cidade como conjunto de funções específicas que deveriam estar articuladas para que o dia a dia urbano fosse supostamente mais organizado e eficiente. Rapidamente esse documento tornou-se uma das principais referências para a arquitetura e o urbanismo modernos, galgando repercussão duradoura. Isso foi um fato marcante e está exemplificado no concurso para o Plano Piloto de Brasília, 26 anos após a publicação do documento. Aponta Laurent Vidal, ao discutir as propostas do certame:

Os projetos apresentados têm um traço comum: sua inspiração racionalista. Cada um, de forma mais ou menos explícita, organiza a cidade em torno das quatro funções principais definidas pela Carta de Atenas: habitar, trabalhar, cultivar o corpo e o espírito, circular. A antiga rua é sistematicamente substituída por uma concepção nova concedendo a prioridade aos espaços livres e blocos isolados. A forma geral dos planos e das partes constitutivas obedecem a uma estrita regularidade geométrica. (VID AL, 2009, p. 203)

O projeto de Lucio Costa, que veio a ser o vencedor do certame, não destoava substancialmente de seus concorrentes nesse aspecto. Partindo de vinte e três pontos textualizados que são desenvolvidos como princípios ao conceituar, caracterizar e dimensionar a cidade, Costa produziu uma coerência interna para o projeto e concedeu-lhe um poder simbólico que manifestava mais patentemente um projeto de modernidade e emancipação social inerentes à ambição do governo do país. Essa dimensão foi destacada pelo júri avaliador. Conforme afirmou Sir William Holford, urbanista inglês membro da banca que julgou os projetos apresentados no concurso:

O modo como eu compreendo este concurso é que ele é um concurso de idéias, não de detalhes. Nenhum arquiteto, firma ou companhia pode preparar, nesta fase, um plano de trabalho definido que abranja detalhes econômicos e sociais custos reais. Portanto, as condições do concurso exigiam somente um esboço do projeto e um memorando ilustrativo das idéias do concorrente. Isto era compulsório. (HOLFORD, 2002, p. 52 sic.)

Constata-se no projeto apresentado por Costa, entretanto, uma síntese de proposições urbanísticas elaboradas desde o período da Revolução Industrial e durante a primeira metade do século XX - caracterizado por uma posição paradigmática dos preceitos do Movimento Moderno e que representavam a face programática da modernidade (HEYNEN, 1999) do norte-global. Entre essas proposições das quais Costa retirou inspiração para o projeto do Plano Piloto de Brasília, são mais evidentes, por exemplo, a Cidade Linear, de Arturo Soria y Mata (1882), e a Cidade 
Jardim, de Ebenezer Howard $(1898,1902)$. O que é, porém, pouco considerado na revisão crítica do projeto são as influências dos processos de urbanização no Brasil, especialmente ao longo do século XIX e XX. Costa era também profundo conhecedor da fundação de novas cidades no sertão do país.

O desejo de tomada de posse do território e a apropriação do ideário moderno europeu fazem parte da mesma narrativa de configuração de Brasília, particularmente na área residencial ao longo do Eixo Rodoviário, formado pela sequência de Superquadras elemento central e estruturante no projeto de Costa. Por outro lado, as Superquadras também referenciam as ideias de Clarence Perry (1923) quando reconsidera o conceito das Unidades de Vizinhança e também fazem lembrar as representações de setores da Ville Radieuse de Le Corbusier (1931).

Para Costa, a concepção das Superquadras dizia respeito também à reaproximação do habitante com o lugar de morada. Escreve:

Quanto ao problema residencial, ocorreu a solução de criar-se uma sequência contínua de grandes quadras dispostas, em ordem dupla ou singela, de ambos os lados da faixa rodoviária, e emolduradas por uma larga cinta densamente arborizada, árvores de porte, prevalecendo em cada quadra determinada espécie vegetal, com chão gramado e uma cortina suplementar intermitente de arbustos e folhagens, a fim de resguardar melhor, qualquer que seja a posição do observador, o conteúdo das quadras, visto sempre num segundo plano e como que amortecido na paisagem. Disposição que apresenta a dupla vantagem de garantir a ordenação urbanística mesmo quando varie a densidade, ca- tegoria, padrão ou qualidade arquitetônica dos edifícios, e de oferecer aos moradores extensas faixas sombreadas para passeio e lazer, independentemente das áreas livres previstas no interior das próprias quadras. (COSTA, 1995, pp. 291-292)

$\mathrm{Na}$ composição de conjunto, o sistema de quatro superquadras formaria a Unidade de Vizinhança ao longo do eixo rodoviário. Nessas unidades haveria a implantação um sistema de parques e recreação, assim como de outros equipamentos de uso coletivo. Nomeadamente: postos de saúde, bibliotecas de bairro, igrejas, escolas e variada sorte de equipamentos de uso comum no interior das superquadras, sempre circundados por locais de comércio adjacentes às vias de tráfego. Caracterizando sua própria proposta, Costa conclui ao afirmar que "é assim que, sendo monumental é também cômoda, eficiente, acolhedora e intima. E ao mesmo tempo derramada e concisa, bucólica e urbana, lírica e funcional" (COSTA, 1995, p. 295).

Dessa maneira, ambicionava uma reconexão entre os residentes e a dimensão bucólica e edilícia, partindo da estruturação e de um relacionamento coerente entre os espaços próximos e circundantes. Esses deveriam ser arborizados e livres, amalgamando aspectos do campo, de uma certa ruralidade, com a cidade (Figura 1). Sob esse pressuposto, Costa indicava que os habitantes teriam a oportunidade de desfrutar do melhor desses dois universos, equacionando o conflito da tradicional dicotomia - real e simbólica - entre campo e cidade, entre o rural e o urbano ${ }^{3}$.

Assim, a composição habitacional em Superquadras, mais recentemente considerada uma das mais importantes inovações no projeto de Costa (EL-DAHDAH, 2005; GORELIK, 2005; 2012; FERREIRA

\footnotetext{
${ }^{3}$ Os clássicos da sociologia não tardaram a apontar como componente central do advento da modernidade europeia em fins do século XIX e início do século XX a transição do rural para o urbano. Essa discussão está presente com mais veemência nos textos de Ferdinand Tönnies (2001 [1887]) e de Georg Simmel (1987[1902]), mas também encontra lastro nos escritos de Émile Durkheim (2004 [1895]). Posteriormente, Henri Lefebvre (1999[1970]; 2012[1968]) tematiza essa dicotomia de forma mais aprofundada e específica. Apesar das diversas interpretações e características das percepções desses autores, há certo consenso em seus trabalhos acerca de como a industrialização e, ato contínuo, a urbanização alteraram os modos de vida e a própria cosmologia social - em oposição ao campo, ao rural e à vida em (pequena) comunidade, colocada em posição dicotômica com relação à vida em sociedade na cidade. Essas discussões reverberaram no campo do urbanismo, cuja consolidação disciplinar ocorreu de maneira quase concomitante com a da sociologia.
} 
O bairro se desenvolve basicamente ao longo das linhas do Metrô, com a constituição de um sistema binário de vias de circulação e o lançamento de quarteirões mistos para residências, comércio e serviços. Paralelamente a estes quarteirões foram dispostas grandes quadras residenciais. Visando o favorecimento das atividades econômicas foi permitida uma grande flexibilidade quanto aos possíveis usos do solo na faixa de quarteirões situados ao longo do Metrô. (ZIMBRES E REIS ARQ. ASSOCIADOS, 1991, pp. 6, sic.)

Em seguida o MDE (Memorial Descritivo) discorre sobre as potenciais volumetrias e também acerca do anseio pelo estabelecimento de uma centralidade para o bairro. Esses elementos são utilizados como recursos para redesenhar um modelo mais próximo da dita cidade tradicional. Nota-se na retórica presente no texto:

A criação de um meio ambiente construído rico e ameno levou à adoção de tipologias variadas, tradicionalmente utilizadas em várias cidades brasileiras. Tratou-se também de assegurar uma grande liberdade de concepção para os futuros projetos das edificações que serão aí construídas. Desta forma combinou-se de maneira feliz virtudes das cidades tradicionais com conquistas do urbanismo contemporâneo.

O comércio estará concentrado especialmente na área central do bairro, nos centros secundários localizados nos entornos de estações do metrô e ao longo de vias que constituem o sistema binário, onde também se localizarão equipamentos públicos, postos de serviços e áreas institucionais para igrejas, associações etc. (ZIMBRES E REIS ARQ. ASSOCIADOS, 1991, p. 8)
Além disso, destaca-se que o metrô, uma demanda que precedeu o projeto urbanístico e que surgia como premissa a incorporar, foi reconhecido como uma contingência aceitável. A linha férrea já havia sido estabelecida e cortava a área para instalação do bairro: era uma divisão substancialmente importante no terreno. Zimbres não pareceu enxergar aí um problema de primeira ordem, então, estabeleceu o projeto urbanístico com a linha a vincar o bairro e sugeriu a edificação de pequenas pontes para superar esse fosso aberto. Algumas das pontes seriam destinadas a veículos, enquanto outras seriam para uso exclusivo de pedestres - inclusive com a sugestão de instalação de comércios em algumas delas (ZIMBRES E REIS ARQ. ASSOCIADOS, 1991).

Zimbres defendia o adensamento, valorizava a presença de pedestres e a mistura de usos, opondo-se principalmente ao modelo do Plano Piloto por considerá-lo uma composição fragmentada e dispersa fundamentalmente na escala residencial do projeto de Costa. Esses componentes ficam expressos nas referências adotadas, como mencionado, mas também no discurso. No projeto urbanístico de Águas Claras e em suas representações (Figura 2, 3 e 4) esses aspectos são demonstrados e indicados, revelando também a inspiração em avenidas e galerias comerciais ao longo das calçadas, no modelo de rua-corredor, com a disposição de menos áreas livres e da composição de uma malha urbana mais compacta e menos permeável, cuja morfologia está pautada no padrão: volume edilício, via pedonal e via de circulação motorizada.

Entretanto, pouco foi mencionado que isso não representou uma negação absoluta do urbanismo do Plano Piloto. Zimbres refere-se aos quarteirões que propõe com cul-de-sac projetados para Águas Claras de "Superquadras" (Figuras 5 e 6), numa óbvia referência às unidades projetadas por Costa ao resgatá-las como elemento retórico para definir as áreas habitacionais de seu próprio projeto. 
Figuras 2, 3 e 4 - Croquis do projeto de Aguas Claras. 1991. Fonte: Ilustrações fornecidas pelo Arq. Urb. Paulo Zimbres. Arquivo pessoal do autor.
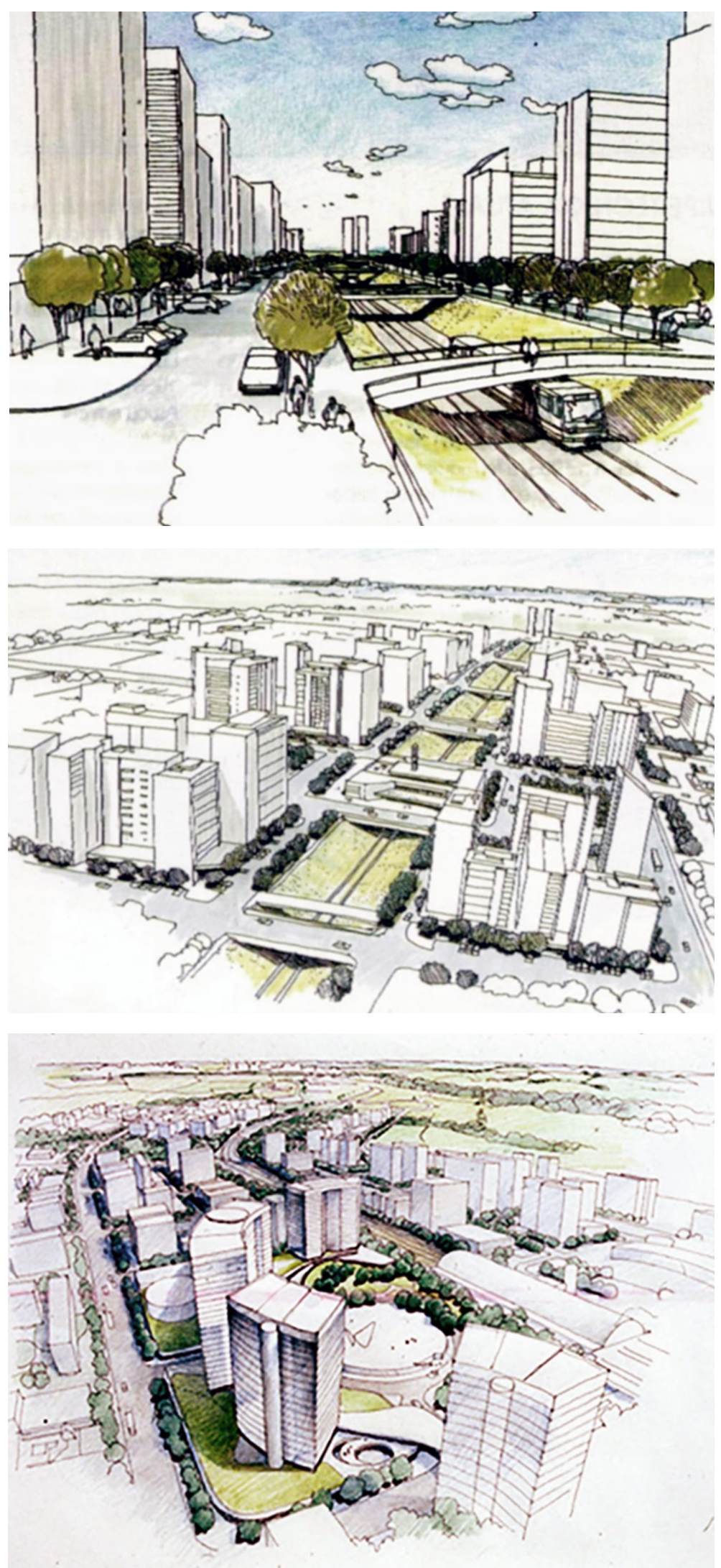

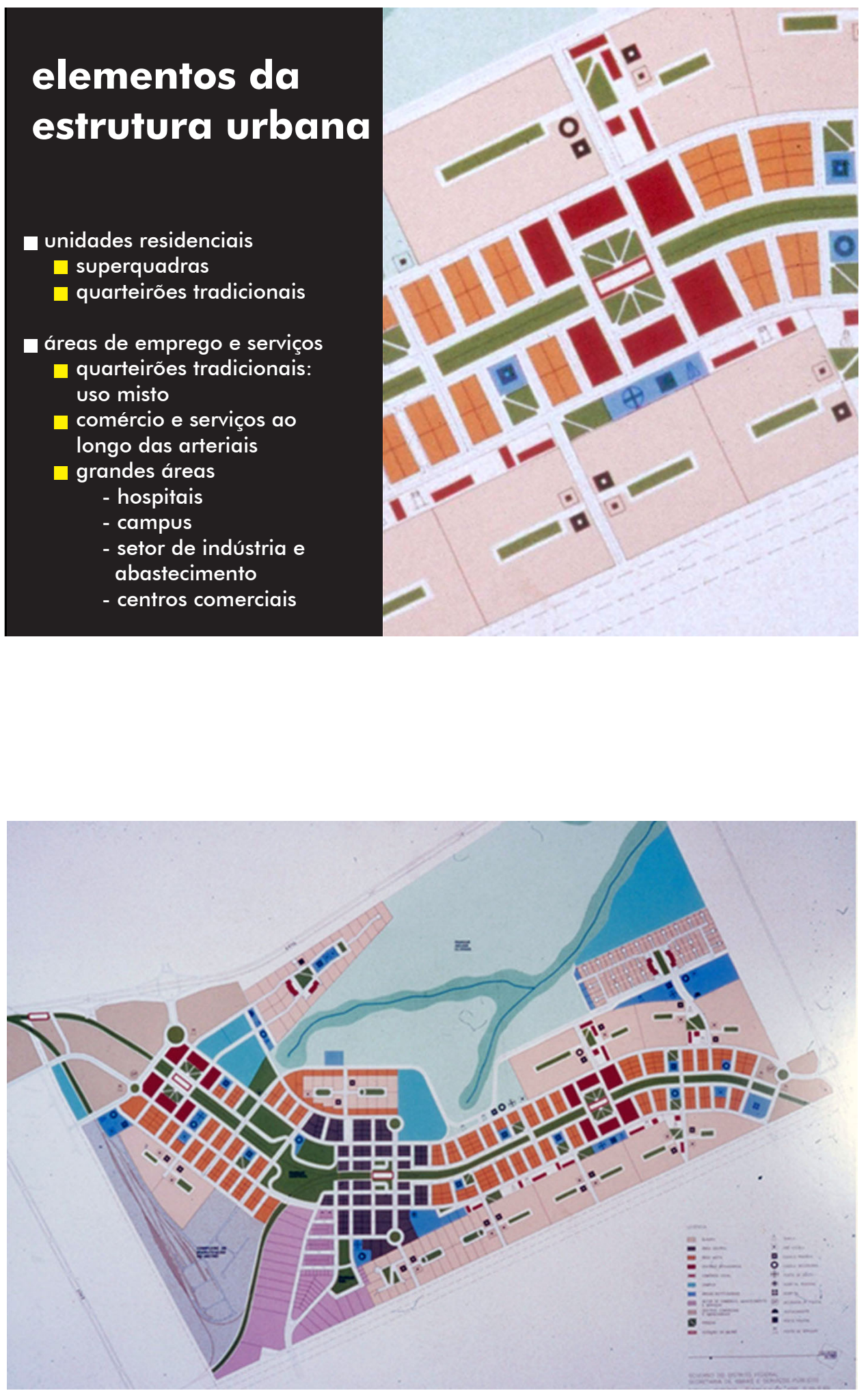

Figura 5 - Trecho da apresentação "Projeto Águas Claras: um exercício de urbanismo no Distrito Federal-1991" e trecho do projeto e representação do Plano de Ocupação do Projeto Águas Claras. 1991.

Fonte: Ilustracõos fornecidas pelo Arq. Urb. Paulo Zimbres. Arquivo pessoal do autor.
Figura 6 - Trecho da apresentação 'Projeto Águas Claras: um exercício de urbanismo no Distrito Federal - 1991" com representação de Plano de Ocupação do Projeto Aguas Claras. 1991.

Fonte: Ilustrações fornecidas pelo Arq. Urb. Paulo Zimbres. Arquivo pessoal do autor. 


\section{ÁGUAS CLARAS: DO FÔLEGO DA CRÍTICA AOS MUROS}

No final dos anos 1950, o Distrito Federal contava com Taguatinga ${ }^{4}$, que já havia sido definida como futura cidade-satélite do Plano Piloto (PAVIANI, 2010a), dada a consolidação cada vez maior do Núcleo Bandeirante - então Cidade Livre. Existiam também assentamentos anteriores à construção, tais como Planaltina e Brazlândia, e um conjunto de ocupações provisórias. Posteriormente, mas, como Taguatinga, também no eixo sudoeste do Distrito Federal, foram instaladas a cidade-satélite de Ceilândia (1971) e mais de dez anos depois, Samambaia (1985). Nesse contexto, Águas Claras não surgiu como mais um projeto urbanístico na região, mas sim como parte de ações governamentais que buscaram alinhar os déficits habitacionais e políticas que visavam o controle social do território (GOUVÊA, 1995). Vale ressaltar que grande parte da propriedade do solo é pública no Distrito Federal, o que possibilitou ao Estado uma ação direta na sua forma de ocupação. Para viabilizar um transporte de massas para Samambaia e outros núcleos urbanos em criação - como Riacho Fundo e Recanto das Emas - e tornar economicamente viável a conexão entre o Plano Piloto e toda a área urbanizada no eixo sudoeste, fazia-se necessária a ocupação de regiões consideradas vazias ao longo do futuro percurso metroviário.

Em 1991, quando foi encomendado o projeto urbanístico ao escritório de Paulo Zimbres, a intenção do governo (PAVIANI, 2010b) ia de encontro ao que o PEOT $^{5}$ de 1977 previa. Conforme indicava o referido documento, o local, distando cerca de $19 \mathrm{~km}$ do Plano Piloto de Brasília, estaria vocacionado para abrigar atividades dos setores terciário e quaternário ${ }^{6}$, não tendo sido previsto o uso habitacional, pois se tratava de área para ocupação de baixa densidade, de modo a preservar a bacia do Paranoá.

A Zimbres, entretanto, foi solicitado um bairro exclusivamente residencial. $\mathrm{O}$ urbanista, por sua vez, não acatou aquilo que lhe fora requerido e elaborou uma proposta que questionava o modelo de ocupação urbana do território com malha urbana horizontal, descontínua e dispersa (Figura 7). Como explica Richard Williams ao analisar o projeto:

$\mathrm{O}$ arquiteto tinha sido chamado para planejar um bairro dormitório; no entanto, em vez disso, ele trabalhou para que o novo assentamento fosse um denso elemento de urbanismo na tradição europeia, projetando com base na experiência dos centros urbanos tradicionais de cidades brasileiras e europeias. De forma bem otimista, nomeou o plano de "Um exercício na urbanização do Distrito Federal". (WILLIAMS, 2007, p. 2)

Em $1992^{7}$ é dada autorização para implantação de Águas Claras como bairro da Região Administrativa III, Taguatinga. Atualmente, porém, Águas Claras é conhecida na região exatamente por ser composta quase que inteiramente por condomínios verticais fechados e edifícios de elevada altura, algo que gera grande contraste diante do contexto urbano de perfil mais baixo e espraiado do conjunto do Distrito Federal. Além disso, ainda que projetada para a valorização do pedestre, no bairro as calçadas em geral são estreitas e ladeadas por grades, empenas cegas, muros ou estacionamentos. Intensos e longos engarrafamentos são também parte da rotina local, evidenciando o elevado uso de transportes motorizados individuais. Algumas contingências bastante específicas acabaram por gerar esses resultados.

\footnotetext{
${ }^{4}$ Taguatinga foi originalmente criada em 1958 com o nome "Vila Sarah Kubitschek", alterado posteriormente. Foi a primeira cidade satélite do Distrito Federal.

${ }^{5}$ PEOT - Plano Estrutural de Organização Territorial (1977), elaborado pela SEPLAN (Secretaria de Planejamento, Distrito Federal).

${ }^{6} \mathrm{O}$ setor terciário da economia refere-se a atividades de prestação de serviços, mas também de comércio de bens. Já o setor quaternário da economia refere-se, principalmente, à produção e compartilhamento de informações e conhecimentos.

${ }^{7}$ Lei $\mathrm{N}^{\mathrm{o}}$ 385, de 16 de Dezembro de 1992.
} 


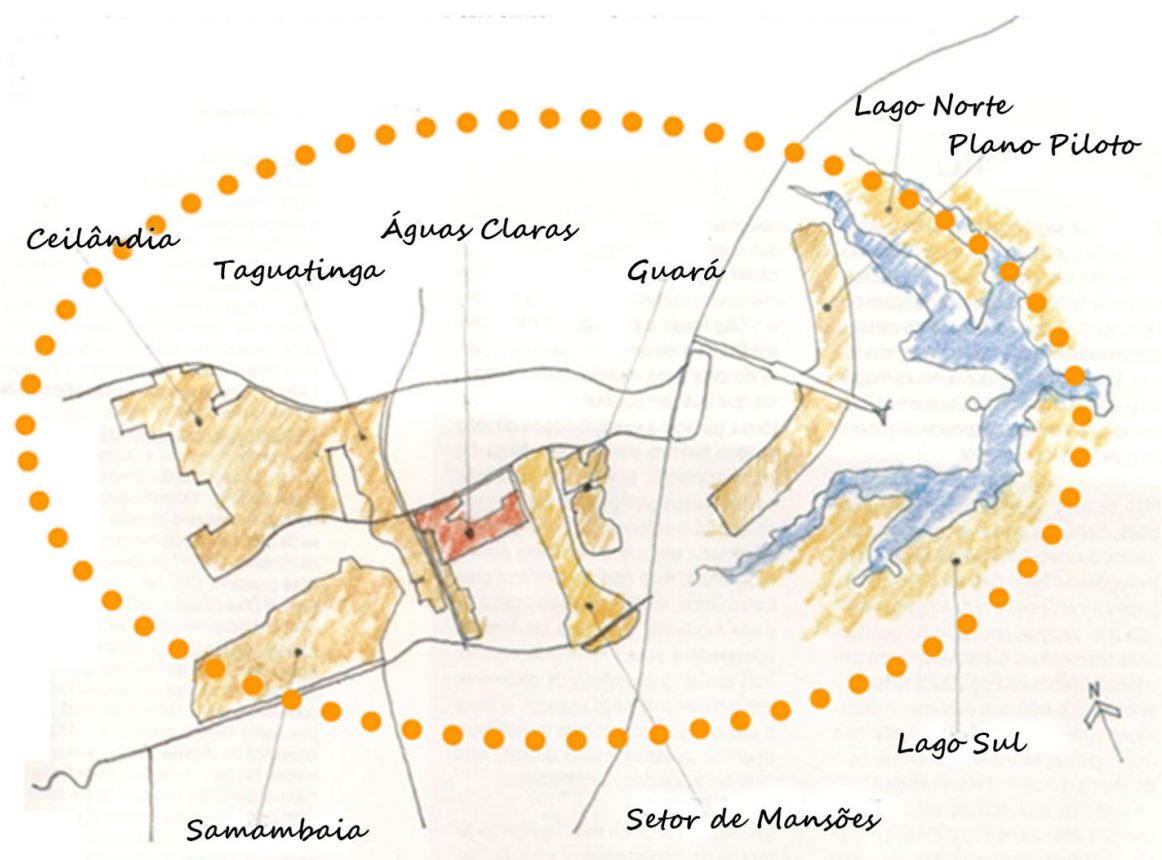

Figura 7 - Estudo de situação produzido por Paulo Zimbres e sua equipe. 1991.

Fonte: Apresentação "Águas Claras: um exercício de urbanismo no Distrito Federal-1991”. Material fornecido pelo Arq. Urb. Paulo Zimbres. Arquivo pessoal do autor.
Desde o princípio da construção, ainda em 1992, os edifícios eram empreendimentos levados a cabo por cooperativas de funcionários públicos, mas esse modelo não prosperou, tendo apresentado incapacidade financeira. Muitas das obras e terrenos acabaram sendo assumidos ou adquiridos por incorporadoras e empresas de construção (SILVA, 2016). Várias das cooperativas foram levadas a declarar falência nesse ínterim. Desse imbróglio, advêm alterações marcantes, como o aumento ou redução da quantidade inicial de edifícios instalados em um mesmo terreno ou a própria arquitetura desses prédios. É também nesse momento que a urbanização de Águas Claras passa a ser submetida mais intensamente à dinâmica do mercado imobiliário, com reflexos nos programas de necessidades dos empreendimentos e também nos preços praticados. Para o governo daquela época era importante a valorização e a rápida ocupação do local e, concomitantemente, a indústria imobiliária estava aquecida e ávida, principalmente diante da valorização imobiliária (SERRANO, 2010) decorrente do aumento da demanda habitacional das classes médias locais ou em afluência para o DF (SILVA, 2016).
Uma segunda contingência importante refere-se ao fato de Águas Claras ter sido fundada como um bairro de Taguatinga, a RA III. Isso significou que o projeto em instalação estava sob regulação da legislação aplicável a Taguatinga. Quando de sua implantação, conforme constante no Plano de Ocupação anexo à Lei No 385 de 16 de Dezembro de 1992, o número máximo de pavimentos para as edificações - inicialmente previstos em até 12 - já foi alterado, saltando para 15. Além disso, ficaram estabelecidos os coeficientes de aproveitamento para todos os tipos de usos: comercial, habitação, misto etc.

É, entretanto, com a aprovação do Plano Diretor Local (PDL) de Taguatinga em $1998^{8}$ que o potencial de transformação em Águas Claras é expandido, com consequências profundas na realidade do bairro (JATOBÁ, 2010). Estando abrigada como bairro da RA III, Águas Claras foi submetida à mesma legislação que então passou a vigorar em Taguatinga, ignorando as especificidades projetuais definidas por Zimbres e sua equipe e as intenções para as quais seu projeto inicial parecia ter sido vocacionado. As

${ }^{8}$ Lei Complementar No 90 de 11 de março de 1998. Plano Diretor Local da Região Administrativa de Taguatinga, RA-III. 
duas consequências mais notáveis desse fato e cujo impacto na paisagem e vivências urbanas merecem destaque são, primeiramente, a mudança do gabarito de 15 - já após primeira alteração - pavimentos máximos para uma ausência de limites, passando a existirem como regulação de limite construtivo somente os coeficientes de aproveitamento que, também alterados, tornaram-se maiores do que anteriormente. $\mathrm{O}$ argumento para essas mudanças, ancorado na lógica de densificação urbana apresentada no PDOT de $1992^{9}$ e relativamente reforçada - principalmente para o eixo sudoeste do DF - no PDOT de $1997^{10}$, era de que com coeficientes de aproveitamento maiores, a ocupação urbana seria otimizada, seriam evitados vazios urbanos e a densidade populacional viria a ser ampliada. Hodiernamente Águas Claras abriga edifícios com até 36 pavimentos.

A segunda consequência diz respeito ao fato de que foi também o PDL de Taguatinga que possibilitou que ruas ladeadas por empenas cegas se tornassem uma figura comum em Águas Claras. Uma convergência de condicionantes criou um ambiente que permitia esse tipo de situação. A legislação em vigor não propiciava estímulos para que as incorporadoras preferissem, por exemplo, dar tratamento que fosse amigável para os pedestres às fachadas dos edifícios ou que optassem por destinar esses espaços à instalação de comércio - incluído nas atividades admitidas e aconselhado como opção. Ainda que haja sim diversos locais em Águas Claras com comércio instalado em fachadas de edifícios ao nível da rua, nota-se em diversas ruas e avenidas que a rua e a interface entre público e privado foi ignorada. Tratava-se de uma decisão delegada às incorporadoras responsáveis pelos empreendimentos. De maneira mais grave, há casos nos quais ocorreu apenas o afloramento de garagens por metros acima do nível da rua - circunstância permitida à época e assumida como op- ção em grande parte dos casos. Relativamente a essa paisagem de grades, muros e empenas, diversos autores realizaram a mesma constatação:

Observa-se nas duas principais avenidas da cidade de Águas Claras uma sequência monótona de edifícios residenciais em lâminas, com garagens e áreas de lazer no pavimento térreo e com barreiras físicas constituídas por muros. (...) na proposta inicial da cidade, em algumas vias, o pavimento térreo abrigava comércio local, porém isso praticamente não ocorreu, pois se percebem garagens ocupando o pavimento térreo, configurando no espaço urbano público longas paredes cegas, e em algumas quadras os pilotis ficaram livres, mas os edifícios são cercados e eliminam a visibilidade necessária para o pedestre nas superquadras tradicionais. (OLIVEIRA M. E., 2009, p. 70)

Ocorre que a legislação permitia o afloramento das garagens, não as considerando como área computável no coeficiente de aproveitamento até o terceiro pavimento de estacionamento construído ${ }^{11}$. Ou seja, construir as garagens acima do solo - o que reduziria drasticamente os custos da obra - não impactava o limite de aproveitamento do empreendimento, visto que não havia um limite de pavimentos, e, portanto, não tinha impacto na quantidade de unidades que seriam colocadas à venda. Em síntese: era uma opção lucrativa para os responsáveis pela construção. Diversas construtoras e incorporadoras escolheram essa possibilidade diante dos elevados custos de escavação e de construção em subsolo. Logo, tornou-se prática difundida entre as empresas responsáveis pela edificação dos empreendimentos optar pelo afloramento, erigindo diversas empenas cegas sem qualquer interface com a rua e que chegam aos 12 metros de altura mesmo em avenidas movimentadas, como é possível

\footnotetext{
${ }^{9}$ Lei No 353 de 18 de Novembro de 1992. Plano Diretor de Ordenamento Territorial, DF.

${ }^{10}$ Lei N 17 de 28 de Janeiro de 1997. Plano Diretor de Ordenamento Territorial, DF.

11 Artigo 72, Seção I, Capítulo III. Lei Complementar No 90 de 11 de março de 1998. Plano Diretor Local da Região Administrativa de Taguatinga, RA-III.
} 

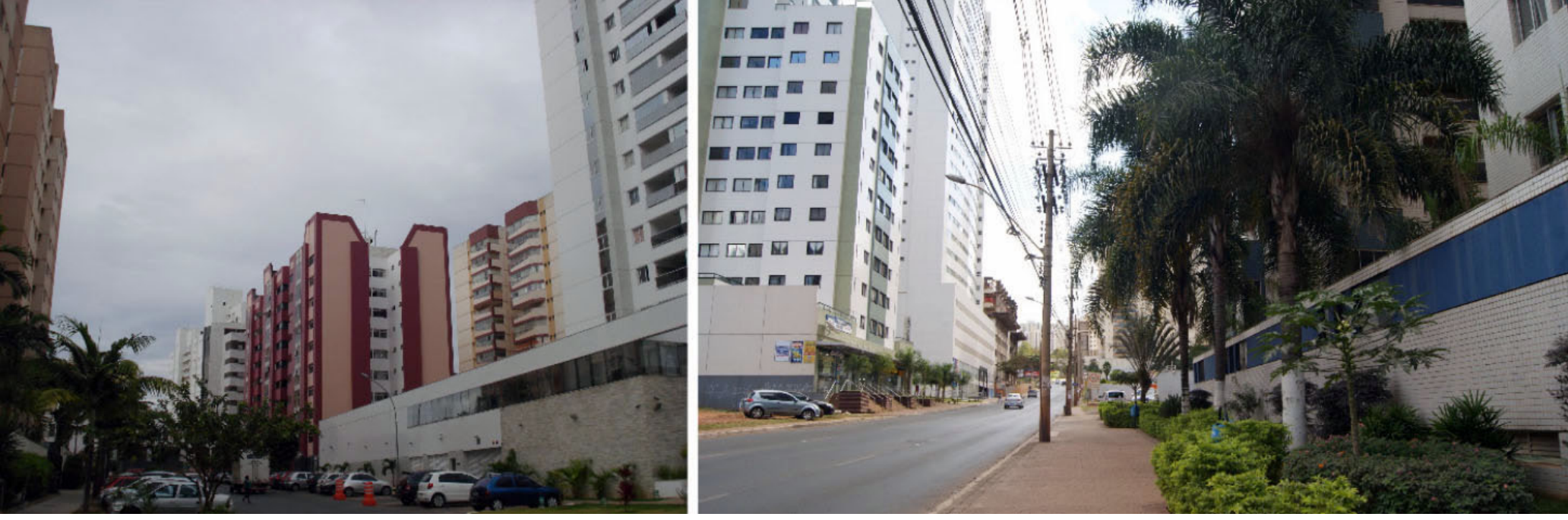

Figura 8 - Fotografias de uma miscelânea de ruas e avenidas de Águas Claras apresentando uma profusão de ocorrências de empenas cegas.

Fonte: arquivo pessoal do autor.
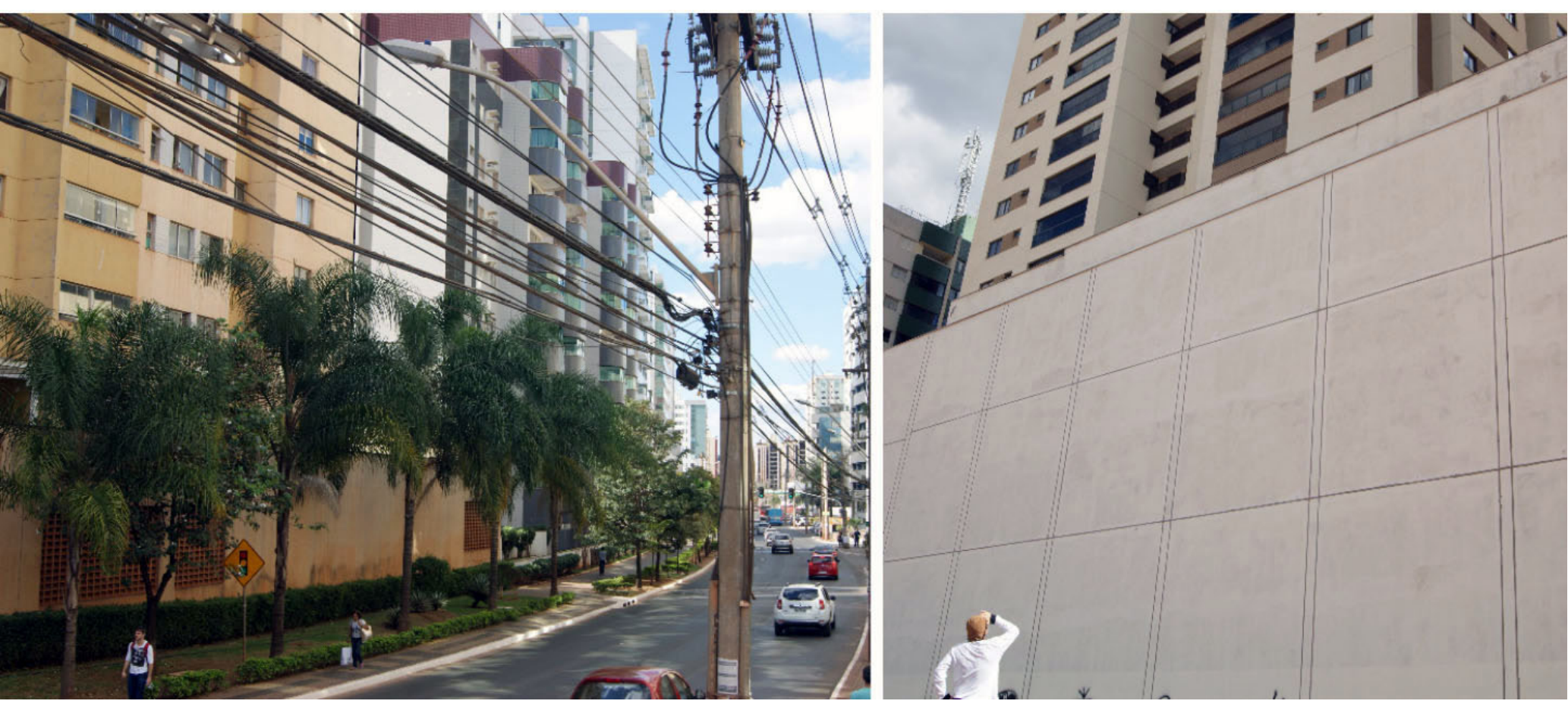

Figura 9 - Fotografias de uma miscelânea de ruas e avenidas de Águas Claras apresentando uma profusão de ocorrências de empenas cegas. Fonte: arquivo pessoal do autor.

notar em fotografias obtidas em diversas observações feitas nas visitas de pesquisa ao bairro (Figuras 8 e 9).

De forma similar, a presença constante de grades e muros ladeando os passeios de pedestres (Figura 10) é outra possibilidade facilitada pela legislação. Ne- nhum dos dois é considerado para efeito de contabilização da taxa de ocupação e, devido a uma demanda local generalizada por instrumentos e artefatos de segurança e controle alimentada por uma política do medo cotidiana, tornaram-se itens comuns. (PEREIRA, 2016) 


\section{CONSIDERAÇÕES FINAIS: SUI GE- NERIS ATÉ QUE PONTO?}

Águas Claras exemplifica como as problemáticas indicadas pela crítica à Brasília atravessam o tempo e vão além do urbanismo moderno. Ainda que apresente pontos com presença de fluxo de pedestres, comércio de rua e atividade no espaço público, predominam áreas ermas, com baixa circulação e que apresentam elementos de constante vigilância e controle que geram incômodo em qualquer passante. Ainda que houvesse a intenção de erigir espaços inspirados na rua corredor em diversos pontos, Águas Claras não foi capaz de resgatar com plenitude os padrões modelados a partir de Edimburgo, Nova Iorque ou Milão, e apresentados por Zimbres como ideais.

Apesar de sua grande importância relacional, visto sua proximidade física e sua história contingenciada pelo Plano Piloto de Brasília, Águas Claras é hoje um dos bairros ${ }^{12}$ de classe média/média-alta ${ }^{13}$ mais característicos da região. Seu projeto foi elaborado no caldeirão da crítica ao urbanismo modernista e adotou como soluções técnicas que visavam retomar lógicas que se propunham distintas. Apesar disso, Águas Claras enfrenta problemas típicos das demais cidades brasileiras, como congestionamentos e trânsito intenso, a presença de interstícios, a falta de conectividade entre trechos da malha urbana e a presença de condomínios fechados, com seus muros, cercas e um grande leque de aparatos de segurança instalados nos edifícios e ruas, alimentados pela insegurança de se estar no espaço público e que, por sua vez, promovem espaços pouco interessantes, pouco confortáveis e, ironicamente, pouco seguros.

Hoje o bairro é comumente associado pela população local a outros contextos urbanos de alta densidade e famosos por edifícios de grandes alturas, como ao ser chamada de "Manhattan candanga", "Manhattan de Brasília" ou "Manhattan brasileira"14. O estabelecimento dessa relação não é apenas pela vaga similaridade percebida no skeyline, que chama à atenção ao contrastar com a baixa altura dos demais edifícios da área urbana e da constante presença do horizonte no Planalto Central. Passa também por circuitos simbólicos de construção de uma distinção em meio ao conjunto metropolitano. Da mesma maneira, sua caracterização como bairro repleto de muros e grades, preenchido por condomínios fechados, é também notória.

Há projeto de urbanismo que sobreviva à sua própria materialização? Essa questão é recorrente e as respostas tendem ser polêmicas, mas o questionamento que traz é pertinente à medida que coloca em cheque a ferramenta e o processo que caracterizam o papel de arquitetos e urbanistas em sua principal contribuição na produção urbana. O que fica mais evidente ao longo da discussão até aqui tecida é a permeabilidade do projeto de urbanismo.

Por um caminho ou por outro, o Distrito Federal abarcou projetos de modernidade que agora estão impressos em seu território e que foram erigidos em meio a conflitos e contingências que, independentes, extrapolam e acabam por subverter a suposta capacidade de modelação da realidade delegada ao urbanismo. Torna-se evidente, por outro lado, como a legislação urbanística é, muito mais do que o projeto, capaz de submeter intenções e condicionar vivências urbanas. Ao fim e ao cabo, este artigo pretende contribuir modestamente para as discussões que ambicionam compreender as relações entre os projetos de urbanismo e o tortuoso percurso até sua materialização enquanto ruas, edifícios e realidade habitada, dialogando com circunstâncias situadas e de fundo legal, social e econômico.

\footnotetext{
${ }^{12}$ A CODEPLAN (Companhia de Planejamento do Distrito Federal) considera que a RA Águas Claras é composta por três subdivisões com características morfológicas e demográficas distintas: Areal, Arniqueiras e Águas Claras Vertical. Essa última subdivisão é aquela sobre a qual se debruça este trabalho.

${ }^{13}$ Como referência, enquanto a renda média nacional era de R\$ 928 em 2018 - quando o salário mínimo correspondia a R\$954 -, em Águas Claras (vertical) mais de 84\% da população possuía renda mínima de R \$ 4.770, com 17\% da população total tendo renda domiciliar superior a R\$19.000 (CODEPLAN, 2018).

${ }^{14}$ Notícias dos sítios eletrônicos: Agenda Capital; Huffpost Brasil; Águas Claras News.
} 
A partir de um caso situado como o de Águas Claras, o projeto que preconizava a retomada do quarteirão como interface do público e privado, paisagem do cotidiano e de apropriação coletiva, esse modelo de investigação ganha sentido. Independentemente de seu projeto original, verificou-se a profunda relação entre configuração urbana, legislação e gestão pública como mediadores da construção do caráter público e privado dos espaços de convívio. Discute-se como o projeto de urbanismo influi e recebe influência ao posicionar-se como elemento motriz na estruturação e no planejamento urbano. São problemáticas que trazem à tona a relevância de pressões exógenas ao próprio projeto urbanístico e que promovem materialidades inicialmente não previstas e seguem, de forma bastante dinâmica, somatizando no espaço construído anseios da população, de agentes do mercado imobiliário e governamentais que negociam na esfera pública e na economia simbólica e de poder locais - ou para além dela. Isso permite explorar ambiguidades valiosas que existem no bojo do termo "projeto", extrapolando não só o sentido que tem ancorado no âmbito do campo específico da arquitetura e do urbanismo, como também problematizando seu papel enquanto dimensão de disputa e conflito na conformação de projetos de cidade, projetos de modos de vida, projetos de região e projetos de futuro.

\section{REFERÊNCIAS BIBLIOGRÁFICAS}

BENEVOlO, L. (2005). História da Cidade (4a ed.). São Paulo: Perspectiva.

BICCA, P. (1985). Brasília: mitos e realidades. Em A. Paviani, \& P. Bicca, Brasília, Ideologia e Realidade: espaço urbano em questão (pp. 101-134). São Paulo \& Brasília: Projetos Editores Associados \& CNPq.

CAMPANHONI, A. (2011). Implantação dos edifícios em Águas Claras-DF: influência no desempenho térmico ambiental dos espaços abertos. Brasília: Universidade de Brasília (Dissertação de mestrado).

CAMPANHONI, A. (2013). Planejamento urbano, cidade compacta e infraestrutura adequada: caso de Águas Claras - DF. Anais do Encontro Nacional da ANPUR (p. x). Recife: ENANPUR.
CARVALHO JÚNIOR, E. B., SOUSA NETO, F., OLIVEIRA, L. F., COSTA, C. A., MELO, W. C., \& GARAVELLI, S. L. (2016). Avaliação do ruído da construção civil na cidade de Águas Claras-DF. Congresso Luso-Brasileiro para o Planejamento Urbano, Regional, Integrado e Sustentável VII, 1-12.

CODEPLAN. (2018). PDAD-Pesquisa Distrital por Amostra de Domicílios: Águas Claras. Brasília: Governo do Distrito Federal.

CORBUSIER, L. (2004[1930]). Précisions. São Paulo: Cosac \& Naify.

COSTA, L. (1995). Lúcio Costa: registro de uma vivência. São Paulo: Empresa das Artes.

DEL RIO, V. (1990). Introdução ao desenbo urbano no processo de planejamento. São Paulo: Editora Pini.

DURKHEIM, É. (2004 [1895]). As Regras do Método Sociológico ( $9^{\mathrm{a}}$ ed.). Lisboa: Editorial Presença.

EL-DAHDAH, F. (2005). Lucio Costa: Brasilia's Superquadra (CASE). NY \& Londond: Prestel.

FERNANDES, W. C., BAPTISTA, G. M., \& BIAS, E. d. (2011). Quantificação do Verde Urbano na Área Urbana da Região Administrativa de Águas Claras, por meio de Modelagem Espectral em Aerofotos Digitais (UltraCamXP). Anais XV Simpósio Brasileiro de Sensoriamento Remoto - SBSR, 1051-1058.

FERREIRA, M. M., \& GOROVITZ, M. (2009). A invenção da Superquadra: o conceito de unidade de vizinhança em Brasília. Brasília: Superintendência do IPHAN no Distrito Federal.

FICHER, S. (2009). Paradigmas urbanísticos de Brasília. Revista da Biblioteca Mário de Andrade, I(65), 86-112.

FRAMPTON, K. (1997). História crítica da arquitetura moderna (1 $1^{a}$ ed.). São Paulo: Martins Fontes.

FRANÇA, F. C. (2008). A indisciplina que muda a arquitetura: a dinâmica do espacso doméstico no Distrito Federal. Brasília: Universidade de Brasília (Tese de doutorado).

GARAVELLI, S. L., MORAES, A. M., NASCIMENTO, J. R., NASCIMENTO, P. H., \& MAROJA, A. M. (2010). Mapa de ruído como ferramenta de gestão da poluição sonora: estudo de caso de Águas Claras - DF. PLURIS: Congresso Luso-Brasileiro para o Planejamento Urbano, Regional, Integrado e Sustentável IV, 1-12.

GEHL, J. (2014). Cidade para pessoas. São Paulo: Perspectiva. 
GORELIK, A. (2005). Das vanguardas a Brasilia: cultura urbana e arquitetura na América Latina. Belo Horizonte: Humanitas - Editora UFMG.

GORELIK, A. (2012). A impossibilidade de (pensar) Brasília. Serrote(10), 238-239.

GOUVÊA, L. A. (1995). Brasília: a Capital da segregação e do controle social - Uma avaliação da ação governamental na área da habitação. São Paulo: Annablume.

HALL, P. (2013[1988]). Cidades do amanhã: uma história intelectual do planejamento e projeto urbanos no século XX $\left(2^{\mathrm{a}} \mathrm{ed}\right.$.). São Paulo: Perspectiva.

HEYNEN, H. (1999). Architecture and modernity: a critique. Massachusetts: MIT Press.

HOLANDA, F. d. (1985a). A morfologia interna da Capital. Em A. Paviani, \& P. Bicca, Brasilia, Ideologia e Realidade: espaço urbano em questão (pp. 135-160). São Paulo \& Brasília: Projeto Editores Associados \& CNPq.

HOLANDA, F. d. (1985b). Arquitetura como Estruturação Social. Em R. FARRET (Org.), O Espaço da Cidade: Contribuição à Análise Urbana (pp. 115-141). São Paulo: Projeto.

HOLFORD, W. (2002). Apreciação do Júri. Perguntadas formuladas pelo Dr. Israel Pinheiro ao urbanista William Holford, presidente da Comissão julgadora, com referência ao resultado do concurso. Em A. J. Buchman, Lúcio Costa o inventor da cidade de Brasilia (pp. 51-59). Brasília: Thesaurus.

HOLSTON, J. (1993[1989]). Cidade modernista: uma cítica de Brasília e sua utopia (2a ed.). São Paulo: Companhia das Letras.

JACOBS, J. (2011[1961]). Morte e vida de grandes cidades (3 ed.). São Paulo: WMF Martins Fontes.

JATOBÁ, S. U. (2010). Crescimento urbano na metrópole de Brasília: potencial e limitações. Em A. P. (org.), F. F. (org.), I. C. (org.), L. C. (org.), \& S. U. (org.) (Eds.), Brasilia 50 anos: da capital à metrópole (pp. 307-338). Brasília: Editora UnB.

KOOLHAAS, R. (Agosto de 2016). Brasília. Revista Centro $(0+)$, online. Fonte: http://revistacentro.org/index.php/ koolhaaspt/

LEFEBVRE, H. (1999[1970]). A revolução urbana. Belo Horizonte: Editora UFMG.

LEFEBVRE, H. (2012[1968]). O Direito à Cidade. Lisboa: Estúdio e Livraria Letra Livre.
LIMA, R. R., \& SOUZA, E. A. (2014). A (In) Sustentabilidade das Edificações Verticalizadas: Estudo de caso em Águas Claras. Anais do III ENANPARQ - Encontro da Associação Nacional de Pesquisa e Pós-Graduação em Arquitetura e Urbanismo, 1-13.

MASCARÓ, J. L. (1987). Desenho urbano e custos de urbanização. Brasília: Ministério da Habitaçao, Urbanismo e Meio Ambiente.

OLIVEIRA, J. A., SPOSITO, R. M., \& BLUMENSCHEIN, R. N. (01 de Abril de 2012). Ferramenta para avaliação da sustentabilidade ambiental na fase de execução de edifícios no Distrito Federal. Revista Gepros - Gestão da Produção, Operacoões e Sistemas, 7(2), pp. 11-21.

OLIVEIRA, M. E. (2009). O processo de estruturação urbana de Aguas Claras-DF: avaliação pós-ocupação. Brasília: Universidade Católica de Brasília (Dissertação de mestrado).

PAVIANI, A. (2010a). A metrópole terciária: evolução urbana socioespacial. Em A. Paviani, F. F. Barreto, I. C. Ferreira, L. C. Cidade, \& S. U. Jatobá (Eds.), Brasília 50 anos: da capital à metrópole (pp. 227-252). Brasília: Editora UnB.

PAVIANI, A. (2010b). O "Projeto Águas Claras" - planejamento desperdiçado. Em A. Paviani, \& A. Paviani (Ed.), Brasilia, a metrópole em crise: ensaios sobre urbanização (pp. 111143). Brasília: Editora UnB.

PEREIRA, L. B. (2016). Modernidade, Mixofobia e a Configuraşão do Espaço Público: questões sobre Civilidade em Aguas Claras, Brasilia-DF. Brasília, Brasil: Faculdade de Arquitetura e Urbanismo-Universidade de Brasília (Dissertação de Mestrado; 313p)

SANTOS, C. N. (1988). A cidade como um jogo de cartas. São Paulo: Projeto Editores.

SECCHI, B. (2009). A cidade do século vinte. São Paulo: Perspectiva.

SERRANO, A. d. (2010). O processo de verticalização em espaços urbanos: o exemplo de Águas Claras-DF. Anais do XVI Encontro Nacional dos Geógrafos (pp. 1-11). Porto Alegre: Associação dos Geógrafos Brasileiros.

SILVA, M. A. (2016). A especulação imobiliária descaracterizando uma ideia: o caso de Águas Claras, no DF. Porto Alegre: Anais do IV ENANPARQ.

SIMMEL, G. (1987[1902]). A metrópole e a vida mental. Em O. G. Velho, O fenômeno urbano (Quarta ed., pp. 11-25). Rio de Janeiro: Editora Guanabara.

TÖNNIES, F. (2001 [1887]). Community and Society. Cambridge: Cambridge University Press. 
VENTURI, R. (2004[1966]). Complexidade e contradição em arquitetura ( $2^{\mathrm{a}}$ ed.). São Paulo: Martins Fontes.

VIDAL, L. (2009). De Nova Lisboa a Brasilia: a invenção de uma capital. Brasília: Editora Universidade de Brasília.

WILLIAMS, R. (2007). Brasília depois de Brasília. Arquitextos, 083.00(07).

ZIMBRES E REIS ARQ. ASSOCIADOS. (1991). Memorial Descritivo do Bairro Águas Claras - MDE 220/90. Brasília: Governo do Distrito Federal.

O financiamento foi realizado pela FAP-DF e pelo CNPq. Os dados dos processos são: 1. FAP-DF: Avaliação dos impactos e análise dos instrumentos urbanísticos (FAP/DF), processo: 12723.60.31740.14072016 - coord: Luciana Saboia (PPGFAU / UnB)

2. CNPq: (Re)configurações do vazio moderno na paisagem urbana em Brasilia (CNPq) Universal 2016 - Processo: 427807/2016-6 